\title{
Monitoring of clinical efficacy and in vitro sensitivity of Plasmodium vivax to chloroquine in area along Thai Myanmar border during 2009-2010
}

\author{
Poonuch Muhamad ${ }^{1}$, Ronnatrai Ruengweerayut ${ }^{2}$, Wanna Chacharoenkul ${ }^{1}$, Kanchana Rungsihirunrat ${ }^{3}$, \\ Kesara Na-Bangchang ${ }^{1 *}$
}

\begin{abstract}
Background: In Thailand, the proportion of Plasmodium vivax infection has become equal to Plasmodium falciparum. Reports of a trend of gradual decline of in vitro sensitivity of $P$. vivax to chloroquine in some areas of the country, together with accumulating evidences of chloroquine resistance $P$. vivax in other parts of the world, emphasize the need for closely and continuously monitoring clinical efficacy in conjunction with in vitro sensitivity of $P$. vivax isolates.
\end{abstract}

Methods: The study was conducted at Mae Tao clinic for migrant workers, Tak Province during March 2008 - August 2009. A total of 130 patients (17 Thais and 113 Burmeses; 64 males and 66 females) with mono-infection of $P$. vivax malaria, aged between 15-60 years and weighing more than $40 \mathrm{~kg}$, were included in the study. Patients received treatment with chloroquine (2,000 $\mathrm{mg}$ chloroquine phosphate over three days) and the anti-relapse drug primaquine (15 mg for 14 days). In vitro sensitivity of $P$. vivax isolates was evaluated by schizont maturation inhibition assay.

Results: All patients showed satisfactory response to treatment. The cure rate was virtually $100 \%$ within the followup period of 42 days. Neither recurrence of $P$. vivax parasitaemia nor appearance of $P$. falciparum occurred during the investigation period. In vitro data showed a stable sensitivity of chloroquine in this area since 2006. Geometric mean and median (95\% Cl) values of $\mathrm{IC}_{50}$ for chloroquine were 100.1 and 134.7 (1.1-264.9) nM, respectively.

Conclusion: In vivo results suggest that the standard regimen of chloroquine was still very effective for the treatment of blood infections with P. vivax in the Thai-Myanmar border area. In vitro sensitivity data however, raise the possibility of potential advent of resistance in the future. Regular monitoring of the chloroquine sensitivity of $P$. vivax is essential to facilitate the early recognition of treatment failures and to expedite the formulation of appropriate changes to the drug policy.

\section{Background}

Plasmodium vivax is responsible for approximately 70 to 80 million cases of malaria worldwide annually, and is the major cause of human malaria in parts of Pacific region and Central and South America [1]. The disease is rarely life-threatening, but morbidity from prolonged illness and the possibility of relapses from a persistent hepatic form (hypnozoite) are of major concern. Plasmodium vivax can only infect reticulocytes, which limits

\footnotetext{
* Correspondence: kesaratmu@yahoo.com

'Pharmacology and Toxicology Unit, Graduate Program in Biomedical

Sciences, Thammasat University, Thailand

Full list of author information is available at the end of the article
}

parasitaemia, usually to densities lower than $100,000 / \mathrm{ml}$ blood. The relapses can occurs weeks, months or years after initial exposure [2]. In Thailand, the proportion of $P$. vivax infection has now been increasing and has become equal to Plasmodium falciparum since 1998. On the western border of Thailand, the incidence of P. vivax has recently been reported as 20 per 1,000 population per year, similarly to that of $P$. falciparum [3]. The blood schizontocide chloroquine and tissue schizontocide primaquine have remained the mainstay chemotherapeutics for the treatment of $P$. vivax infection in Thailand for more than 60 years, with conserved clinical efficacy of virtually $100 \%$ [3-5]. To date, there 
has been no clinical-parasitological evidence of chloroquine-resistant $P$. vivax in Thailand. Nevertheless, a trend of gradual decline of in vitro sensitivity to chloroquine has been documented in some areas of the country, particularly Thai-Myanmar border [6,7]. Furthermore, the accumulating reports of chloroquine resistance $P$. vivax in other parts of the world during the past three decades including Papua New Guinea [8-11], Indonesia [12], Irian Jaya [13-16], Guyana South America [17], Peru [18], Colombia [19], India [20], Myanmar [21-23], Vietnam [24], Turkey [25], and Ethiopia [26] emphasize the need for closely and continuously monitoring clinical efficacy in conjunction with in vitro sensitivity of $P$. vivax isolates.

The objectives of the present study were to assess in vivo efficacy of first-line regimen of chloroquine given with primaquine, and in vitro susceptibility of $P$. vivax isolates in areas along the Thai-Myanmar border to chloroquine and the new antifolate WR99120.

\section{Methods}

\section{Study site}

The study was conducted at Mae Tao clinic for migrant workers, Tak Province during March 2008 - August 2009. Malaria is a serious imported medical problem in this area with a low and stable disease transmission with two seasonal peaks and forest-related during MayAugust and November-January of each year. Anopheles minimus and Anopheles dirus are the principal vectors. $P$. falciparum and $P$. vivax are the two predominant species with an incidence of 1:1, Plasmodium malariae is occasionally found and Plasmodium ovale is rare [3]. All age groups are affected and nearly all the $P$. vivax infections are symptomatic. The study was approved by the Ethics Committee of the Ministry of Public Health of Thailand.

\section{Assessment of in vivo efficacy of chloroquine/primaquine Patient recruitment and follow-up}

A total of 130 patients (17 Thais and 113 Burmeses; 64 males and 66 females) with mono-infection with $P$. vivax malaria, aged between 15-60 years (target population) and weighing more than $40 \mathrm{~kg}$ were included in the study. Inclusion criteria included a parasitaemia of 1,000100,000 parasites $/ \mu \mathrm{l}$ blood, no signs of severe disease, no anti-malarial treatment during the preceding four weeks, no history of hepatic or kidney diseases. Written informed consent for study participation was obtained from all patients. All were admitted to the clinic during the three-day course of chloroquine and were requested to return for follow-up on days 7, 14, 21, 28, 35 and 42 after treatment initiation. Patients who developed fever or signs/symptoms of malaria were asked to return to the clinic for malaria blood examination.
On enrolment, each patient underwent a physical examination. A symptom questionnaire was also completed. Parasite counts, body temperature and blood for in vitro sensitivity test $(1 \mathrm{ml}$ blood collected into sodium heparinized plastic tube).

\section{Evaluation of clinical efficacy}

The efficacy of chloroquine when given with primaquine for the treatment of $P$. vivax malaria were assessed by (i) the proportion of patients with cure (cure rate), i.e., those who showed clearance of parasitaemia in the peripheral blood and absence of reappearance of parasitaemia within 42 days after treatment initiation, (ii) the parasite clearance time (PCT: the time taken for the parasite count to fall below the level of microscopic detection), and (iii) the fever clearance time (FCT: the time taken for the temperature to return to normal, i.e., $<37.3^{\circ} \mathrm{C}$ and remain so for at least 24 hours).

\section{Treatment}

Patients received treatment with chloroquine given concurrently with primaquine for eradication of hepatic stages of $P$. vivax parasites. Chloroquine (Government Pharmaceutical Organization of Thailand, $250 \mathrm{mg}$ chloroquine phosphate per tablet) at a total dose of 2,000 $\mathrm{mg}$ given over 3 days ( $500 \mathrm{mg}$, four times at 0 and 6-12 hours on day-0, followed by $500 \mathrm{mg}$ daily for two days) and primaquine (Government Pharmaceutical Organization of Thailand, $15 \mathrm{mg}$ base given daily for 14 days starting from the second day of chloroquine treatment and then once daily until day-14). All drugs were administered with a glass of $250 \mathrm{ml}$ drinking water under the supervision of medical staff. Subjects were closely observed for at least 30 minutes after each drug ingestion.

Patients whose parasitaemia was not cleared or those who had a reappearance of $P$. vivax were to be treated with the same regimen of chloroquine and primaquine but the dose of primaquine was to be increased to $20 \mathrm{mg}$. Patients who developed parasitaemia with P. falciparum during the investigation period were to be given a three-day treatment with oral artesunate $(600$ $\mathrm{mg}$ given in doses of $200 \mathrm{mg}$ at 0,6 and 24 hours) in combination with mefloquine $(1,250 \mathrm{mg}$ given as 750 and $500 \mathrm{mg}$ at 6-8 hours apart).

\section{Laboratory investigations}

Following the first dose of drug administration, parasite counts (from finger-prick blood samples) were performed in all patients at six hourly intervals until two consecutive slides yielded negative results, and then during the follow-up period until day 42. Blood films were stained with Giemsa and examined by light microscope. Asexual stages of $P$. vivax were counted against 1,000 erythrocytes in thin blood films or against 200 white blood cells in thick films. The examination was reported as negative 
only after at least 200 fields of the thick film had been examined without encountering a parasite. Parasite species, morphology, and parasitaemia were assessed by microscopic examination.

\section{In vitro drug sensitivity assay}

The schizont maturation assay was performed with $P$. vivax field isolates collected from all patients using a modified method of Russell and colleagues [27]. The concentration of serum added to the culture medium was increased from 10 to $30 \%$. Plasmodium vivax field isolates were tested for their sensitivities against chloroquine and WR99210 at the concentration ranges of 0-10,000 nM for chloroquine (chloroquine phosphate: Liverpool School of Tropical Medicine, University of Liverpool, UK) and 0-2,560 nM for WR99210 (Jacobus Pharmaceutical Inc, Princeton, NJ, USA). The doseresponse curve was analysed by nonlinear regression analysis using CalcuSyn ${ }^{\mathrm{TM}}$ software (Biosoft ${ }^{\mathrm{TM}}$, Cambridge, UK). The results were expressed as inhibitory concentrations (IC) 10, 50 and 90, which are defined as the concentrations of chloroquine or WR99120 producing 10, 50 and 90\% inhibition of parasite development as compared to the control. Quality control of the assay was implemented by parallel determination of the $\mathrm{IC}_{50}$ of chloroquine against chloroquine-sensitive and chloroquine-resistant $P$. falciparum clones.

\section{Results}

\section{Clinical efficacy}

A total of 130 patients with $P$. vivax malaria were included in the study and all had completed a 42 days follow-up period. Demographic and clinical data are summarized in Table 1. All patients showed good response following treatment with median $(95 \% \mathrm{CI})$ values for FCT and PCT of 30 (18-36) and 24 (12-40) h, respectively. The cure rate following treatment was $100 \%$; there was no patient with reappearance of parasitaemia during the 42 days followup. None developed P. falciparum parasitaemia during the investigation period.

\section{In vitro sensitivity}

In vitro sensitivity assay was performed in all of the 130 fresh $P$. vivax isolates collected; 32 (24.6\%) with initial parasitaemia between 2,120 and 64,360 parasites/ $\mu l$ were successfully assessed for in vitro sensitivity to chloroquine and WR99120. All isolates completely developed to mature schizont within 20-40 h depending on dominant stage prior to testing. Despite the variation of the started parasite stages, abnormality in parasite morphology was observed in all wells exposed to the test drugs. Table 2 summarizes the $\mathrm{IC}_{10}, \mathrm{IC}_{50}$ and $\mathrm{IC}_{90}$ values of chloroquine and WR99120. Marked variation in $\mathrm{IC}_{50}$ values were observed for both chloroquine and
WR99120. Geometric mean and median $(95 \% \mathrm{CI})$ values of $\mathrm{IC}_{50}$ for chloroquine were 100.1 and 134.7 (1.1-264.9) $\mathrm{nM}$, respectively. Based on the cut-off $\mathrm{IC}_{50}$ of $100 \mathrm{nM}$ used to classify chloroquine resistance in P. falciparum [28], 20 and 12 isolates, respectively exhibited $\mathrm{IC}_{50}$ values of < and > $100 \mathrm{nM}$, respectively. Geometric mean and median $(95 \% \mathrm{CI})$ values of $\mathrm{IC}_{50}$ for WR99120 were 112.7 and $139.9(0.2-523.0) \mathrm{nM}$, respectively.

\section{Discussion}

Difficulty in controlling vivax malaria is due to its biological characteristics of repeated pre-erythrocytic development due to relapse, with the maximum survival span of hypnozoites of five years [3]. Radical treatment of the infection, therefore, normally consists of a blood schizontocidal course of chloroquine and a course of primaquine for the elimination of the hypnozoites as antirelapse therapy [29]. In most parts of the world, chloroquine remains the first-line treatment for $P$. vivax infection in pregnant and non-pregnant individuals [1]. In the present study, all of the $P$. vivax patients enrolled in the study were satisfactorily treated with the standard regimen of chloroquine with primaquine. All responded well to treatment, with no reappearance of $P$. vivax parasitaemia (recrudescence or relapse) or appearance of $P$. falciparum in peripheral blood during the 42 days follow-up. There was no sign of delayed parasitological and clinical response. The PCT (30 h) and FCT (24 h) were similar to our previous observation in 2006 [5] and a recent observation [30] in the same area. Double infection with $P$. falciparum and $P$. vivax is common in certain malaria-endemic areas of Thailand. The occurrence of subsequent $P$. falciparum following treatment of $P$. vivax malaria has been reported to be less frequent than that of $P$. vivax after treatment of P. falciparum [31]. One possible explanation is the action of primaquine on pre-erythrocytic and eryhtrocytic forms of $P$. falciparum [32]. In addition, all patients stayed in malaria non-endemic area during the follow up period, which excluded the possibility of re-infection. So far, there has been no reported case of chloroquine resistant $P$. vivax in Thailand. Data from previous studies in different endemic areas including Thai-Cambodian and ThaiMyanmar borders during 1989 to 2011 [4-7,32] all indicated full sensitivity of $P$. vivax to standard dose of chloroquine. In a recent multicenter randomized, doubleblind, non-inferiority trial conducted in Cambodia, India, Indonesia and Thailand (Mae Sot and Mae Ramat), a 42-day cure rate of chloroquine given with primaquine was $100 \%$ [32]. Nevertheless, a recent clinical trial in Ethiopia confirmed resistance of $P$. vivax to chloroquine with a 28 -day cure rate of $7.5 \%$ [33]. Reappearance of $P$. vivax parasitaemia beyond day 28 which is suggested to be due to true relapse due to primaquine failure [29], and the relapse rates within 1-6 months were reported to 
Table 1 Demographic and clinical data of patients with $P$. vivax infection included in the study

\begin{tabular}{|c|c|}
\hline & Number $(\%)$ or median $(95 \% \mathrm{Cl})$ \\
\hline \multicolumn{2}{|l|}{ Patient characteristics: } \\
\hline Number included & 130 (64 females, 66 males) (17 Thais, 113 Burmeses) \\
\hline Age [years: median $(95 \%$ Cl)] & $22(15-55)$ \\
\hline Admission parasitaemia [/ $\mu$ l: median $(95 \% \mathrm{Cl})]$ & $4,898(1,206-29,480)$ \\
\hline \multicolumn{2}{|l|}{ Clinical outcome: } \\
\hline Number (\%) completed 42 days follow-up & $130(100)$ \\
\hline Number (\%) cured by day 42 & $130(100)$ \\
\hline PCT [h: median $(95 \% \mathrm{Cl})]$ & $30(18-36)$ \\
\hline FCT [h: median (95\% Cl)] & $24(12-42)$ \\
\hline
\end{tabular}

Data are presented as number (\%) or median (95\% Cl).

PCT (parasite clearance time): The time taken for the parasite count to fall below the level of microscopic detection.

FCT (fever clearance time): the time taken for the temperature to return to normal, i.e., $<37.3^{\circ} \mathrm{C}$ and remain so for at least 24 hours.

be $5-18 \%$ in adult patients both in Thailand and in other tropical areas $[14,29]$. Clinical effectiveness of primaquine as an anti-relapse and patients' compliance could not be evaluated in this short follow-up investigation period.

The in vitro sensitivity data based on schizont maturation inhibition test [27] demonstrated more or less the stability of sensitivity of $P$. vivax isolates in this area of Thailand to chloroquine [geometric mean $\mathrm{IC}_{50}$ of 100.1, median (95\%CI) of 134.7 (1.17-264.9) nM] since 2002 $[27,34]$. Sensitivity of $P$. vivax to chloroquine was shown to be increased by about 2 -fold $\left(\mathrm{IC}_{50}\right.$ : from 131 to $71 \mathrm{nM}$ ) in the presence of primaquine, which also possesses direct blood schizontocidal activity [5]. It was noted that the $\mathrm{IC}_{50}$ of chloroquine in $P$. vivax was about 2 -fold of that of $P$. falciparum, but the variation is probably higher with $P$. vivax [35]. A previous study conducted in the same area for monitoring of in vitro susceptibilities and molecular markers of resistance of $P$. falicparum isolates to chloroquine, quinine, mefloquine and artesunate [35] showed the reversed sensitivity of chloroquine after a period of about 40 years withdrawal from first-line treatment for falciparum malaria, with median (95\% CI) $\mathrm{IC}_{50}$ of chloroquine of 73 (10-164) nM. One (4\%), 19 (73\%) and 6 (23\%) isolates were classified as chloroquine-sensitive, moderately resistant and highly resistant $P$. falciparum, respectively. In other studies, about 3-4 fold higher $\mathrm{IC}_{50}$ of chloroquine was observed in $P$. vivax compared with $P$. falciparum $[35,36]$. This may imply intrinsic characteristic (innate resistance) of $P$. vivax in response to chloroquine. The in vitro cut-off value defining clinically relevant chloroquine resistance in $P$. vivax malaria has yet to be clearly defined. For P. falciparum, cut-off $\mathrm{IC}_{50}$ of $100 \mathrm{nM}$ was used to define chloroquine resistance. Suwanarusk and colleagues [37] defined the cut-off $\mathrm{IC}_{50}$ of $220 \mathrm{nM}$ based on the $35^{\text {th }}$ percentile of the clinical failure rate of $65 \%$ observed in Indonesian patients with $P$. vivax malaria. In the same study [37], the $\mathrm{IC}_{50}$ of chloroquine in Thai isolates collected from Mae Sot District, Thai-Myanmar border (same area as the present study) was also found to be significantly lower than that from Indonesian isolates (geometric mean $\mathrm{IC}_{50}$ of 312 vs $46.8 \mathrm{nM}$ ). Eleven out of 81 Thai isolates (13.6\%) exhibited $\mathrm{IC}_{50}$ of chloroquine over $220 \mathrm{nM}$. Based on this criteria, six out of 32 isolates $(18.8 \%)$ observed in the present study showed $\mathrm{IC}_{50}$ of greater than $220 \mathrm{nM}$. The current in vivo and in vitro results suggest that chloroquine is still an effective firstline treatment for P. vivax in Thailand. Resistance level may remain obviously below the threshold of detectability by the in vivo method. It is noted that definitive

Table 2 Sensitivity of $P$. vivax to chloroquine and WR99120; data are presented as geometric mean and median (95\% Cl) values of $\mathrm{IC}_{10}, \mathrm{IC}_{50}$ and $\mathrm{IC}_{90}$ obtained from 32 isolates

\begin{tabular}{|c|c|c|c|}
\hline Drugs & Inhibitory Concentration (IC) & Geometric mean (nM) & Median (range) (nM) \\
\hline \multirow[t]{3}{*}{ Chloroquine } & $I C_{10}$ & 3.3 & $4.2(0.2-7.1)$ \\
\hline & $\mathrm{I}_{50}$ & 100.1 & $134.7(1.1-264.9)$ \\
\hline & $\mathrm{I}_{90}$ & 2956.5 & $4134.9(7.1-11535.0)$ \\
\hline \multirow[t]{3}{*}{ WR99210 } & $I_{10}$ & 4.9 & $5.7(0.04-17.8)$ \\
\hline & $\mathrm{I}_{50}$ & 112.7 & $139.9(0.2-523.0)$ \\
\hline & $\overline{I_{90}}$ & 2585.0 & $3406.9(1.1-15356.0)$ \\
\hline
\end{tabular}

IC 10,50 and 90 : drug concentrations which produced 10, 50 and 90\% inhibition of parasite development, respectively, as compared to the control (analysed by nonlinear regression analysis using CalcuSyn ${ }^{\mathrm{TM}}$ software). 
conclusion on the efficacy of chloroquine is not appropriate since chloroquine was given with primaquine, and the fact that the study design did not include control arm with chloroquine monotherapy due to ethical reason. Regular monitoring of the chloroquine sensitivity of $P$. vivax is essential as to facilitate the early recognition of treatment failures and to expedite the formulation of appropriate changes to the drug policy. Alternative treatment options for $P$. vivax infection in case of chloroquine resistance may include a three-day course of quinine given concurrently with primaquine [5] or artemisinin combination therapy [38].

Various in vitro assay systems with different endpoint criteria have also been applied for monitoring of sensitivity of $P$. vivax isolates to anti-malarial drugs. Direct comparison of in vitro sensitivity data using different methods should however, be interpreted with caution. Since $P$. vivax infection is predominantly asynchronous, the microscopic method based on inhibition of parasite's growth previously developed by our group [39] is considered the best-suited method for assessing sensitivity of $P$. vivax to anti-malarial drugs [40]. The test method based on schizont maturation inhibition used in the present study, although may be less accurate, but the method is extremely less labour-intensive, more applicable for field studies and does not require expensive or dangerous reagents (monoclonal antibodies or radioisotopes). Unluckily, the success rate of in vitro sensitivity test observed in the current study was relatively low (24.6\%), which is possibly due to variation in asynchronicity of parasite isolates in this area. Russel et al [41] demonstrated the marked stage-specific activity of chloroquine with variable growth rates. Isolates initially at the trophozoite stage had significantly higher chloroquine $\mathrm{IC}_{50}$ values than those initially at the ring stage. Synchronous isolates which reached the target of $40 \%$ schizonts in the control wells within 30 hours had significantly higher geometic mean $\mathrm{IC}_{50}$ of chloroquine. In vitro susceptibility was found to be correlated with initial stage of the parasite, with isolates predominantly at the trophozoite stage having a 2 -fold increase in $\mathrm{IC}_{50}$ values compared to those of parasites predominantly at the ring stage [41].

The spread of chloroquine resistance in $P$. falciparum has led to the use of the antifolate combination sulphadoxine-pyrimethamine (SP) as the first-line drug for malaria treatment in several countries including Thailand, where $P$. vivax and $P$. falciparum often co-exist and occur at approximately equal frequencies [3]. In vitro sensitivity of WR99210, a novel inhibitor of enzyme dihydrofolate reductase (DHFR) was assessed in our study in view of previous reports showing its promise as a possible treatment of $P$. vivax malaria. The drug shows activity against the most pyrimethamine-resistant $P$. falciparum strains and extremely effective inhibitor of the $P$. vivax DHFR including mutations that confer high-level resistance to pyrimethamine $[42,43]$. Median $(95 \% \mathrm{CI}) \mathrm{IC}_{50}$ of WR99120 in P. vivax isolates collected in the present study was $139.9(0.21-523.0) \mathrm{nM}$. The relatively poor in vitro susceptibility of $P$. vivax to WR99120 observed was similar to our previous observation in the same area [44], could be explained by the slow action of this drug and/or the innate resistance as well as the presence of $p$-aminobenzoic acid and folate in the media used which acted as competitive antagonists of antifolate activity [45].

The combination of new antifolates, like WR99210, that are effective against SP-resistant parasites, with appropriate partners, may also play an important role in a rational drug treatment strategy.

\section{Conclusions}

Chloroquine is still sufficiently effective for blood schizontocidal therapy in areas along the Thai-Myanmar border. In vitro sensitivity data however raise the possibility of potential advent of resistance in the future. Regular monitoring of chloroquine sensitivity of $P$. vivax is essential.

\section{Acknowledgements}

The study was supported by The Commission on Higher Education, Ministry of Education of Thailand and The National Research University Project of Thailand (NRU), Office of Higher Education Commission. We thank Ms. Kulaya Ruengweerayut and Dr. Kanungnit Congpuong (Malaria Division, Ministry of Education) for their kind support for sample collection.

\section{Author details}

'Pharmacology and Toxicology Unit, Graduate Program in Biomedical Sciences, Thammasat University, Thailand. ${ }^{2}$ Mae-Sot General Hospital, MaeSot, Tak Province, Thailand. ${ }^{3}$ College of Public Health, Chulalongkorn University, Thailand.

\section{Authors' contributions}

PM performed all the laboratory analysis. RR participated in patients' recruitment and sample collection. WC performed data analysis. KR participated in in vitro sensitivity analysis. KN participated in the design of the study, manage the study and finalize the manuscript. All authors read and approved the final manuscript.

\section{Competing interests}

The authors declare that they have no competing interests.

Received: 7 October 2010 Accepted: 16 February 2011 Published: 16 February 2011

\section{References}

1. Mueller I, Galinski MR, Baird JK, Carlton JM, Kochar DK, Alonso PL, del Portillo HA: Key gaps in the knowledge of Plasmodium vivax, a neglected human malaria parasite. Lancet Infect Dis 2009, 9:555-566.

2. Looareesuwan S, Wilairtana P, Krudsood S, Treeprasertsuk S, Singhasivanon P, Bussaratid V, Chokjindachai W, Viriyavejakul P, Chalermrut K, Walsh DS, White NJ: Chloroquine sensitivity of Plasmodium vivax in Thailand. Ann Trop Med Parasitol 1999, 93:225-230.

3. Vijaykadga S, Rojanawatsirivej C, Cholpol S, Phoungmanee D, Nakavej A Wongsrichanalai C: In vivo sensitivity monitoring of mefloquine monotherapy and artesunate-mefloquine combinations for the treatment of uncomplicated falciparum malaria in Thailand in 2003. Trop Med Int Health 2006, 11:211-219. 
4. Luxemburger C, Van Vugt M, Jonathan S, McGready R, Looaresuwan S, White NJ, Nosten F: Treatment of vivax malaria in an endemic area on the western border of Thailand. Trans R Soc Trop Med Hyg 1999, 93:433-438.

5. Tasanor O, Ruengweerayut R, Sirichaisinthop J, Congpuong K, Wernsdorfer WH, Na-Bangchang K: Clinical-parasitological response and in-vitro sensitivity of Plasmodium vivax to chloroquine and quinine on the western border of Thailand. Trans R Soc Trop Med Hyg 2006, 100:410-418.

6. Tan-ariya $P$, Na-Bangchang $K$, Tin T, Limpaibul L, Brockelman CR, Karbwang J: Clinical response and susceptibility in vitro of Plasmodium vivax to the standard regimen of chloroquine in Thailand. Trans $R$ SOC Trop Med Hyg 1995, 89:426-429.

7. Congpuong K, Na-Bangchang K, Thimasarn K, Tasanor O, Wernsdorfer WH: Sensitivity of Plasmodium vivax to chloroquine in Sa Kaeo province, Thailand. Acta Trop 2002, 83:117-121.

8. Rieckmann $\mathrm{KH}$, Davis DR, Halton DC: Plasmodium vivax resistance to chloroquine. Lancet 1989, 2:1183-1184, 9.

9. Schuurkamp GJ, Spicer PE, Kereu RK, Bulungol PK: A mixed infection of vivax and falciparum malaria apparently resistant to 4 -aminoquinoline: a case report. Trans R Soc Trop Med Hyg 1989, 83:607-608.

10. Whitby M, Wood G, Veenendaal JR, Rieckmann K: Chloroquine-resistant Plasmodium vivax. Lancet 1989, 2:1395-1399.

11. Collignon P: Chloroquine resistance in Plasmodium vivax. J Infect Dis 1991, 164:222-223.

12. Schwartz LK, Lackritz EM, Patchen LC: Chloroquine resistant Plasmodium vivax from Indonesia. NEJM 1991, 324:927-933.

13. Baird JK, Basri H, Bangs MJ, Subianto B, Patchen LC, Hoffman SL: Resistance to chloroquine by Plasmodium vivax in Irian Jaya, Indonesia. Am J Trop Med Hyg 1991, 44:547-452.

14. Murphy GS, Basri H, Andersen EM, Bangs MJ, Mount DL, Gorden J, Sorensen K, Mount DL, Lal AA, Purwokusumo AR, Harjosuwarno S, Hoffman SL: Vivax malaria resistant to treatment and prophylaxis with chloroquine. Lancet 1993, 341:96-100.

15. Fryauff DJ, Tuti S, Mardi A, Masbar S, Patipelohi R, Leksana B, Kain KC, Bangs MJ, Richie TL, Baird JK: Chloroquine-resistant Plasmodium vivax in transmigration settlements of West Kalimantan, Indonesia. Am J Trop Med Hyg 1998, 59:513-518.

16. Sumawinata IW, Leksana B, Sutamihardja A, Subianto B, Fryauff DJ, Baird JK: Very high risk of therapeutic failure with chloroquine for uncomplicated Plasmodium falciparum and $P$. vivax malaria in Indonesian Papua. Am J Trop Med Hyg 2003, 68:416-420.

17. Phillips EJ, Keystone JS, Kain KC: Failure of combined chloroquine and high-dose primaquine therapy for Plasmodium vivax malaria acquired in Guyana, South America. Clin Infect Dis 1996, 23:1171-1173.

18. Ruebush TK, Zegarra J, Cairo J, Andersen EM, Green M, Pillai DR, Marquiño W, Huilca M, Arévalo E, Garcia C, Solary L, Kain KC: Chloroquineresistant Plasmodium vivax malaria in Peru. Am J Trop Med Hyg 2003, 69:548-552.

19. Soto J, Toledo J, Gutierrez P, Luzz M, Llinas N, Cedeño N, Dunne M, Berman J: Plasmodium vivax clinically resistant to chloroquine in Colombia. Am J Trop Med Hyg 2001, 65:90-93.

20. Garg M, Gopinathan N, Bodhe P, Kshirsagar NA: Vivax malaria resistant to chloroquine: case reports from Bombay. Trans R Soc Trop Med Hyg 1995, 89:656-657.

21. Marlar-Than, Myat-Phone-Kyaw, Aye-Yu-Soe, Khaing-Khaing-Gyi, MaSabai, Myint-Oo : Development of resistance to chloroquine by Plasmodium vivax in Myanmar. Trans R Soc Trop Med Hyg 1995, 89:307-308.

22. Myat-Phone-Kyaw, Myint-Oo, Myint-Lwin, Thaw-Zin, Kyin-Hla-Aye, NweNwe-Yin : Emergence of chloroquine-resistant Plasmodium vivax in Myanmar (Burma). Trans R Soc Trop Med Hyg 1993, 87:687.

23. Guthmann JP, Pittet $A$, Lesage A, Imwong M, Lindegardh $N$, Min Lwin M, Zaw T, Annerberg A, de Radiguès X, Nosten F: Plasmodium vivax resistance to chloroquine in Dawei, southern Myanmar. Trop Med Int Health 2008, 13:91-98.

24. Phan GT, de Vries PJ, Tran BQ, Le HQ, Nguyen NV, Nguyen TV, Heisterkamp SH, Kager PA: Artemisinin or chloroquine for blood stage Plasmodium vivax malaria in Vietnam. Trop Med Int Health 2002, 7:858-864
25. Kurcer MA, Simsek $Z$, Kurcer $Z$ : The decreasing efficacy of chloroquine in the treatment of Plasmodium vivax malaria, in Sanliurfa, south-eastern Turkey. Ann Trop Med Parasitol 2006, 100:109-113.

26. Teka H, Petros B, Yamuah L, Tesfaye G, Elhassan I, Muchohi S, Kokwaro G, Aseffa A, Engers $\mathrm{H}$ : Chloroquine-resistant Plasmodium vivax malaria in Debre Zeit, Ethiopia. Malar J 2008, 7:220.

27. Russell BM, Udomsangpetch R, Rieckmann KH, Kotecka BM, Coleman RE, Sattabongkot J: Simple in vitro assay for determining the sensitivity of Plasmodium vivax isolates from fresh human blood to antimalarials in areas where P. vivax is endemic. Antimicrob Agents Chemother 2003, 47:170-173.

28. Pickard AL, Wongsrichanalai C, Purfield A, Kamwendo D, Emery K, Zalewski C, Kawamoto F, Miller RS, Meshnick SR: Resistance to antimalarials in Southeast Asia and genetic polymorphisms in pfmdr1. Antimicrob Agents Chemother 2003, 47:2418-2423.

29. Bunnag D, Karbwang J, Thanavibul A, Chittamas S, Ratanapongse Y, Chalermrut K, Bangchang KN, Harinasuta T: High dose of primaquine in primaquine resistant vivax malaria. Trans $R$ Soc Trop Med Hyg 1994, 88:218-219.

30. Khantikul N, Butraporn P, Kim HS, Leemingsawat S, Tempongko MA, Suwonkerd W: Adherence to antimalarial drug therapy among vivax malaria patients in northern Thailand. J Health Popul Nutr 2009, 27:4-13.

31. Pukrittayakamee S, Vanijanonta S, Chantra A, Clemens R, White NJ: Blood stage antimalarial efficacy of primaquine in Plasmodium vivax malaria. J Infect Dis 1994, 169:932-935.

32. Poravuth $Y$, Socheat $D$, Rueangweerayut $R$, Uthaisin $C$, Pyae Phyo A, Valecha N, Rao BH, Tjitra E, Purnama A, Borghini-Fuhrer I, Duparc S, Shin CS, Fleckenstein L: Pyronaridine-artesunate versus chloroquine in patients with acute Plasmodium vivax malaria: a randomized, double-blind, noninferiority trial. PLoS One 2011, 6:1-12.

33. Yohannes $A M$, Teklehaimanot $A$, Bergqvist $Y$, Ringwald P: Confirmed vivax resistance to chloroquine and effectiveness of artemether-lumefantrine for the treatment of vivax malaria in Ethiopia. Am J Trop Med Hyg 2011, 84:137-140.

34. Baird JK, Wiady I, Fryauff DJ, Sutanihardja MA, Leksana B, Widjaya H, Subianto B: In vivo resistance to chloroquine by Plasmodium vivax and Plasmodium falciparum at Nabire, Irian Jaya, Indonesia. Am J Trop Med Hyg 1997, 56:627-631.

35. Chotivanich K, Udomsangpetch R, Chierakul W, Newton PN, Ruangveerayuth R, Pukrittayakamee S, Looareesuwan S, White NJ: In vitro efficacy of antimalarial drugs against Plasmodium vivax on the western border of Thailand. Am J Trop Med Hyg 2004, 70:395-397.

36. Chaijaroenkul W, Wisedpanichkij R, Na-Bangchang K: Monitoring of in vitro susceptibilities and molecular markers of resistance of Plasmodium falciparum isolates from Thai-Myanmar border to chloroquine, quinine, mefloquine and artesunate. Acta Trop 2010, 113:190-194.

37. Suwanarusk R, Russell $B$, Chavchich $M$, Chalfein $F$, Kenangalem $E_{1}$ Kosaisavee V, Prasetyorini B, Piera KA, Barends M, Brockman A, Lek-Uthai U, Anstey NM, Tjitra E, Nosten F, Cheng Q, Price RN: Chloroquine resistant Plasmodium vivax: in vitro characterisation and association with molecular polymorphisms. PLoS One 2007, 2:e1089-e1096.

38. Douglas NM, Anstey NM, Angus BJ, Nosten F, Price RN: Artemisinin combination therapy for vivax malaria. Lancet Infect Dis 2010, 10:405-416.

39. Tasanor O, Noedl H, Na-Bangchang K, Congpuong K, Sirichaisinthop J, Wernsdorfer WH: An in vitro system for assessing the sensitivity of Plasmodium vivax to chloroquine. Acta Trop 2002, 83:49-61.

40. Wernsdorfer WH, Tasanor O, Wernsdorfer G: In vitro drug sensitivity testing in Plasmodium vivax. Wien Klin Wochenschr 2008, 120:30-33.

41. Russell B, Chalfein F, Prasetyorini B, Kenangalem E, Piera K, Suwanarusk R, Brockman A, Prayoga P, Sugiarto P, Cheng Q, Tjitra E, Anstey NM, Price RN: Determinants of in vitro drug susceptibility testing of Plasmodium vivax. Antimicrob Agents Chemother 2008, 52:1040-1045.

42. Hastings MD, Porter KM, Maguire JD, Susanti I, Kania W, Bangs MJ Sibley CH, Baird JK: Dihydrofolate reductase mutations in Plasmodium vivax from Indonesia and therapeutic response to sulfadoxine plus pyrimethamine. J Infect Dis 2004, 189:744-750

43. Leartsakulpanich U, Imwong M, Pukrittayakamee S, White NJ, Snounou G, Sirawaraporn W, Yuthavong Y: Molecular characterization of dihydrofolate reductase in relation to antifolate resistance in Plasmodium vivax. Mol Biochem Parasitol 2002, 119:63-73. 
44. Rungsihiranrat K, Na-Bangchang K, Hawkins VN, Mungthin M, Sibley C: Sensitivity to antifolates and genetic analysis of Plasmodium vivax isolates from Thailand. Am J Trop Med Hyg 2007, 76:1057-1065.

45. Chulay JD, Watkins WM, Sixsmith DG: Synergistic antimalarial activity of pyrimethamine and sulfadoxine against Plasmodium falciparum in vitro. Am J Trop Med Hyg 1984, 33:325-330.

doi:10.1186/1475-2875-10-44

Cite this article as: Muhamad et al:: Monitoring of clinical efficacy and in vitro sensitivity of Plasmodium vivax to chloroquine in area along Thai Myanmar border during 2009-2010. Malaria Journal 2011 10:44.

Submit your next manuscript to BioMed Central and take full advantage of:

- Convenient online submission

- Thorough peer review

- No space constraints or color figure charges

- Immediate publication on acceptance

- Inclusion in PubMed, CAS, Scopus and Google Scholar

- Research which is freely available for redistribution

Submit your manuscript at www.biomedcentral.com/submit
() Biomed Central 